\title{
Crusted scabies due to indiscriminate use of glucocorticoid therapy in infant ${ }^{*}$
}

\author{
Fernanda Carvalho da Rocha Lima ${ }^{1}$ \\ Manuela Boleira Sieiro Guimarães ${ }^{1}$ \\ Fernanda Helena Craide ${ }^{1}$
}

\author{
Ana Maria Mósca Cerqueira ${ }^{1,2,3,4}$ \\ Carolina Barbosa de Sousa Padilha ${ }^{1}$ \\ Marina Bombardelli ${ }^{1}$
}

DOI: http:/ /dx.doi.org/10.1590/abd1806-4841.20174433

\begin{abstract}
Crusted or Norwegian scabies is a parasitic infectious disease caused by Sarcoptes scabiei var. hominis that mainly affects immunocompromised individuals and those with neurological patients. We report a case of crusted scabies in a 4-monthold infant who had been treated erroneously for atopic dermatitis with high doses of corticosteroids. This initial misdiagnosis associated with the abusive use of corticosteroid facilitated the evolution of scabies to crusted scabies and its main complications of secondary infection and sepsis.
\end{abstract}

Keywords: Adrenal cortex hormones; Glucocorticoids; Scabies; Sepsis

\section{INTRODUCTION}

Scabies is a parasitic disease caused by Sarcoptes scabiei variant hominis. The main form of transmission is personal contact. Less often, transmission through indirect contact occurs through fomites, such as clothing and sheets.

Worldwide prevalence is estimated is 300 million cases per year. The disease can occur in any geographical area, age, race or social group. Precarious hygiene conditions and crowded places are important risk factors. ${ }^{2,3}$

Differential diagnoses are, among others, seborrheic dermatitis, atopic dermatitis, ichthyosis and psoriatic erythroderma. ${ }^{1}$

Crusted scabies, or Norwegian scabies, is a rare and highly contagious form of scabies, characterized by the presence of numerous parasites in the horny layer of the skin. In most cases, it is associated with an underlying disease and mainly affects immunocompromised individuals due to conditions such as lymphoma, acquired immunodeficiency syndrome, immunosuppressive and corticosteroid treatment, malnutrition, institutionalization and mental illness. ${ }^{3,4}$ It presents as thick, scaling, hyperkeratotic lesions, affecting the whole body, mainly the face, neck, scalp and subungual region. ${ }^{5}$ Affected individuals harbor thousands of parasites, thus the disease is highly contagious. ${ }^{6}$ It is associated with increased morbidity and mortality due to the frequent occurrence of secondary infection and evolution to sepsis. ${ }^{2}$

\section{CASE REPORT}

A previously healthy four-month-old mulatto boy, was admitted to our service with a history of lesions miliaria rubra-like on the neck and folds of the upper and lower limbs that had been present for two months. At that time, he was referred to a pediatrician, who prescribed a powder formulation with bismuth subgallate and zinc oxide, associated with a cream with ketoconazole, betamethasone dipropionate and neomycin sulfate, applied for one month throughout the body. After this period, since there was no improvement in the condition, prednisolone $(0.8 \mathrm{mg} / \mathrm{kg} /$ day for seven days, orally) was prescribed in association to potassium permanganate in topical solution. Due to the refractoriness of the condition, the pediatrician prescribed a single-dose ampoule of betamethasone, intramuscularly. Since then the lesions have spread to the trunk, face and scalp, and have become crusty. The child was finally referred to the dermatology clinic with the diagnosis of "severe seborrheic dermatitis".

The mother, a 16-year-old teenager, was followed throughout pregnancy and presented all negative serological tests (VDRL, hepatitis B, toxoplasmosis and HIV). She denied any type of intercurrence except the need for topical treatment for scabies during pregnancy. She also said that the child was born healthy.

At physical examination, the patient presented multiple erythematous papules and crusted and erythematous lesions dis-

Received on 06.02.2015

Approved by the Advisory Board and accepted for publication on 03.03.2015

Study conducted at General Polyclinic of Rio de Janeiro and at Jesus Municipal Hospital- Rio de Janeiro (RJ), Brazil.

Financial support: none.

Conflict of interest: none.

Dermatology Service of the General Polyclinic of Rio de Janeiro (PGRJ) - Rio de Janeiro (RJ), Brazil.

Dermatology Service of Jesus Municipal Hospital - Rio de Janeiro (RJ), Brazil.

Dermatology Service of Naval Marcílio Dias Hospital (HNMD) - Rio de Janeiro (RJ), Brazil.

Dermatology Service of Bonsucesso Federal Hospital - Rio de Janeiro (RJ), Brazil.

(C2017 by Anais Brasileiros de Dermatologia 
seminated in the body, mainly affecting the trunk and the scalp. Important nail dystrophy and fissures in the abdomen were evident. He was hypoactive, tachycardic, febrile, with cushingoid facies and anasarca. In face of this situation, our main diagnostic hypothesis was crusted or Norwegian scabies, associated with secondary infection and sepsis (Figures 1 and 2).

The mother and the grandparents complained of important pruritus, especially nocturnal. At physical examination, they presented erythematous and hyperchromic papules disseminated mainly in the abdomen and back, compatible with scabies (Figure 3).

Dermoscopy several parasites, represented by triangular (delta-shaped) structures or similar to millipedes (Figures 4 and 5). Skin biopsy was then conducted, laboratory tests were requested, and the infant was hospitalized in a pediatric hospital.

Histopathology revealed tunnels in the horny layer with the presence of the parasite (Figure 6). Laboratory tests revealed signif-

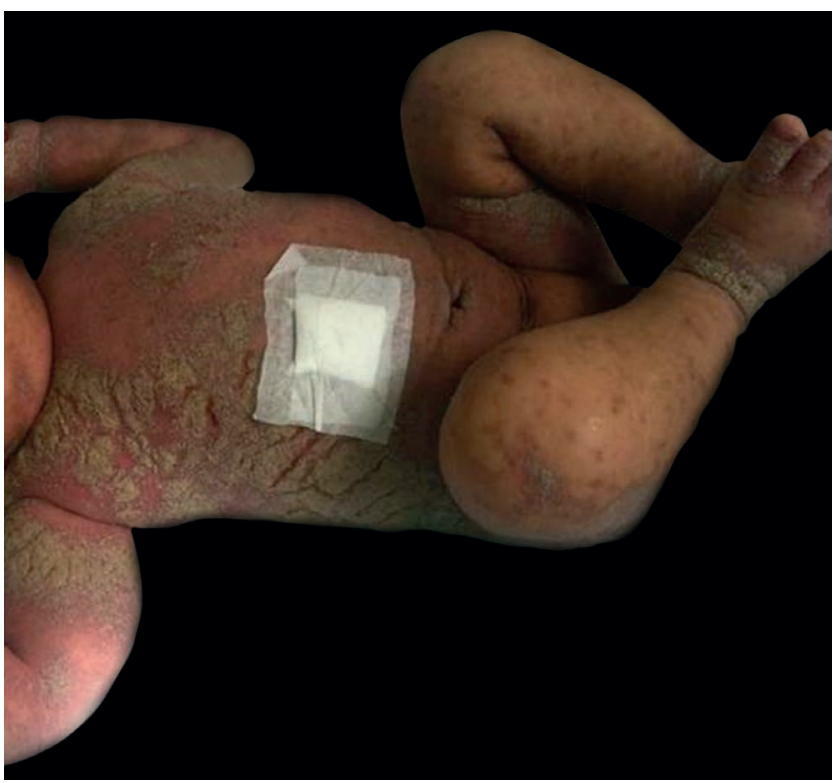

Figure 1: Erythema and widespread hyperkeratotic plaque

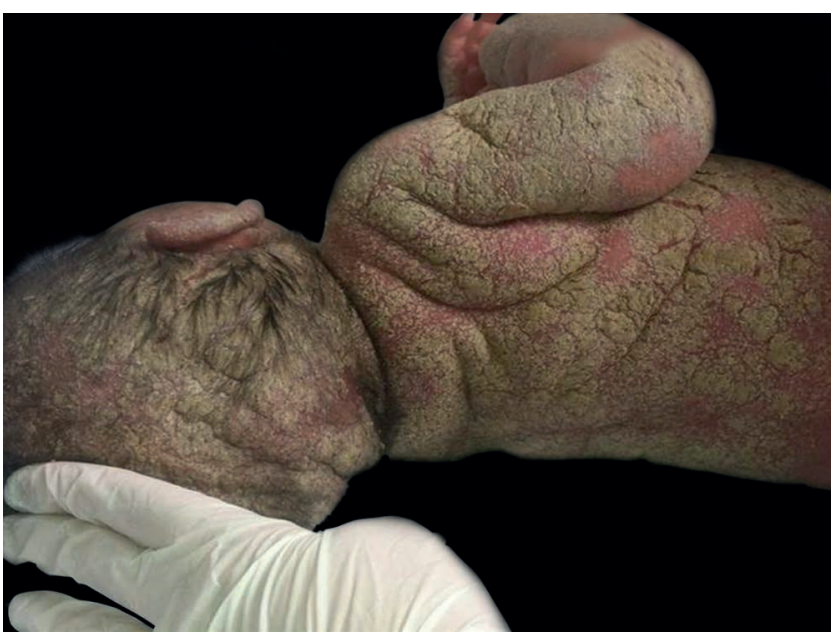

FIGURE 2: Significant involvement of the scalp and clefts in the trunk icant leukocytosis with left shift, thrombocytopenia, and increased levels of inflammatory markers.

Intravenous antibiotic therapy, topical application of permethrin lotion $1 \%$ once daily and contact isolation was then established. Family members were treated with oral ivermectin and top-

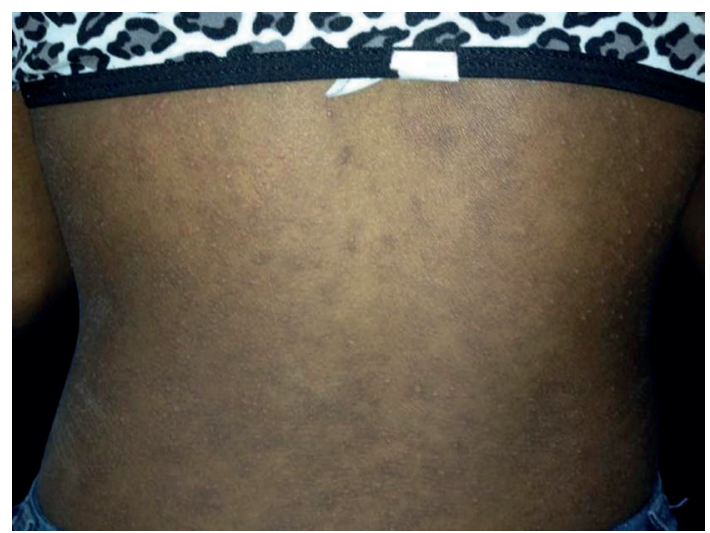

FIGURE 3: Mother presenting brownish erythematous papules and excoriations

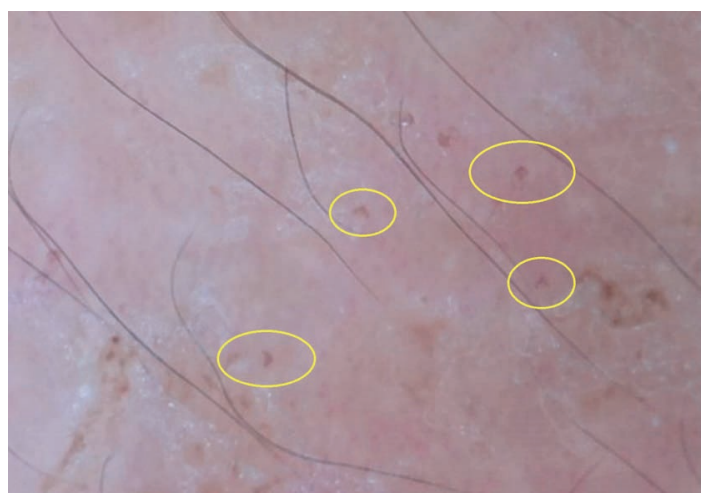

FIGURE 4: Dermoscopy of the child's inflammatory lesion: triangular structures (delta-shaped), which represent the parasite's head and front paws (x10)

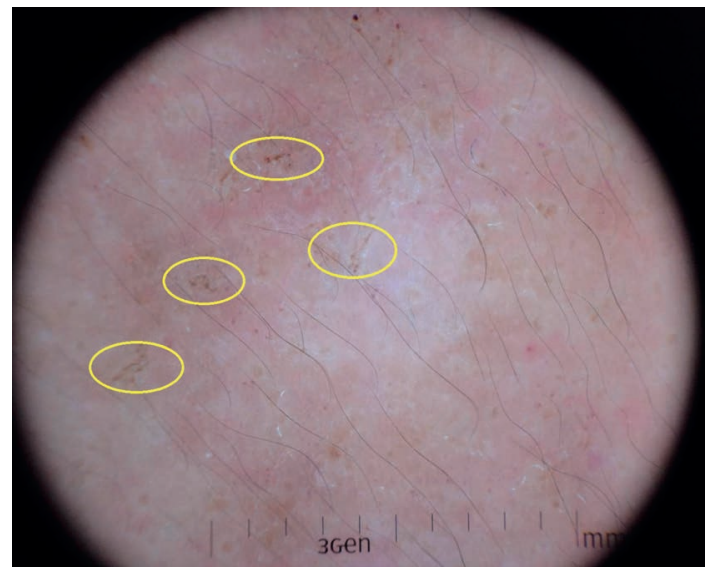

Figure 5: Dermoscopy of the child's lesion: structures similar to millipedes, compatible with the tunnels excavated by the parasite $(x 10)$ 


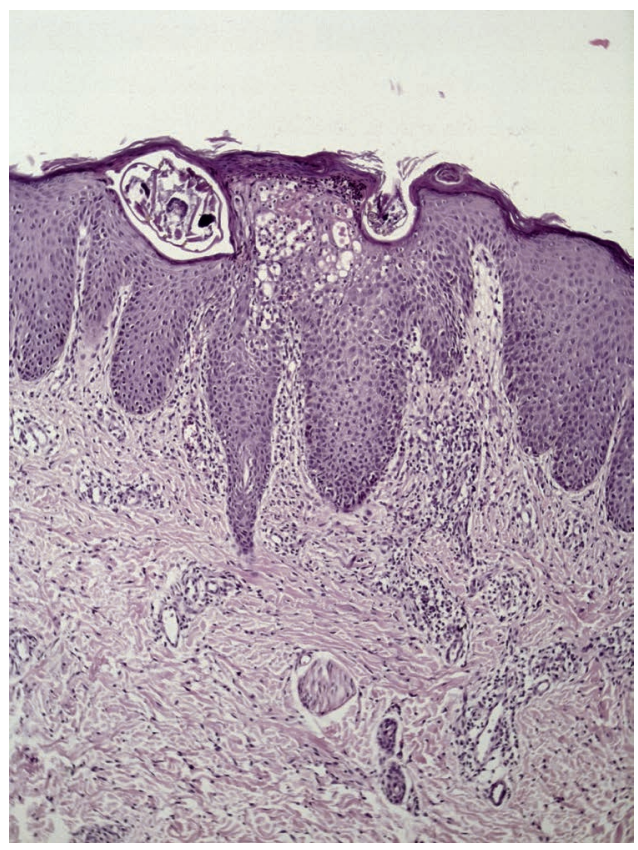

FIGURE 6: Histopathology: Psoriasiform acanthosis with tunnels in the stratum corneum and presence of the parasite and its waste $(\times 40)$

ical permethrin lotion 5\%. On the tenth day of hospitalization, the patient presented improvement of cutaneous lesions, but the condition evolved with septic shock and, despite the treatment instituted in the intensive care unit, there was cardiac arrest and death.

\section{DISCUSSION}

We describe a case of dramatic evolution of crusted scabies. The diagnosis of scabies at the onset of the disease is essential so that there is no evolution to the crusted form, especially in immunosuppressed patients. This diagnosis is often neglected by non-specialists, mainly in children, because of its variable clinical presentation. It is also important to look at family history and to research the symptomatology in close relatives - which, in this case, would have helped a lot in the initial elucidation, since the mother, had already been treated for scabies during pregnancy, and showed signs and symptoms of active disease. Unfortunately, the child was not treated correctly initially, and the use of high-potency topical corticosteroids over a long period of time on a large extent of the skin, associated with the use of high-dose oral and intramuscular corticosteroids, led to immunosuppression, which facilitated the secondary infection and sepsis.

\section{REFERENCES}

1. Pouessel G, Dumortier J, Lagrée M, Pierre MH, Ganga-Zandzou PS, Ythier H, et al. Scabies: a common infection in children. Arch Pediatr. 2012;19:1259-60.

2. Binić I, Janković A, Jovanović D, Ljubenović M. Crusted (Norwegian) scabies following systemic and topical corticosteroid therapy. J Korean Med Sci. 2010;25:188-91

3. Hengge UR, Currie BJ, Jäger G, Lupi 0, Schwartz RA. Scabies: a ubiquitous neglected skin disease. Lancet Infect Dis. 2006;6:769-79.

4. Subramaniam G, Kaliaperumal K, Duraipandian J, Rengasamy G. Norwegian scabies in a malnourished young adult: a case report. J Infect Dev Ctries. 2010;4:349-51.

5. Walton SF, Currie BJ. Problems in Diagnosing Scabies, a Global Disease in Human and Animal Populations. Clin Microbiol Rev. 2007;20:268-79.

6. Zafar AB, Beidas SO, Sylvester LK. Control of transmission of Norwegian scabies. Infect Control Hosp Epidemiol. 2002;23:278-9.
MAILING ADDRESS:

Fernanda Carvalho da Rocha Lima

Avenida Nilo Peçanha, 38, 6th floor - Centro

20020-100 - Rio de Janeiro, RJ

Brazil

Email:ferochalima@hotmail.com

How to cite this article: Lima FCR, Cerqueira AMM, Guimarães MBS, Padilha CBS, Craide FH, Bombardelli M. Crusted scabies due to indiscriminate use of glucocorticoid therapy in infant. An Bras Dermatol. 2017;92(3):383-5. 